\title{
School age outcome of hospitalisation with respiratory syncytial virus infection of prematurely born infants
}

\author{
A Greenough, ${ }^{1}$ J Alexander, ${ }^{2}$ P Boit, ${ }^{2} \mathrm{~J}$ Boorman, ${ }^{3}$ S Burgess, ${ }^{4}$ A Burke, ${ }^{5}$ P A Chetcuti, ${ }^{4}$ \\ I Cliff, ${ }^{2}$ W Lenney, ${ }^{2}$ T Lytle, ${ }^{3}$ C Morgan, ${ }^{5}$ C Raiman, ${ }^{1}$ N J Shaw, ${ }^{5}$ K P Sylvester, ${ }^{1}$ \\ J Turner ${ }^{6}$
}

- Additional appendix and figure are published online only at http://thorax.bmi.com/content/ vol64/issue6

${ }^{1}$ King's College London, MRCAsthma Centre, Division of Asthma, Allergy and Lung Biology, London, UK; ${ }^{2}$ University Hospital of North Staffordshire, Stoke on Trent, UK: ${ }^{3}$ Abbott Laboratories, Maidenhead, UK; ${ }^{4}$ Leeds General Infirmary, Leeds, UK; ${ }^{5}$ Liverpool Women's Hospital, Liverpool, UK; ${ }^{6}$ Premier Research Group, Crowthorne, UK

Correspondence to: Professor A Greenough, 4th Floor, Golden Jubilee Wing, King's College Hospital, London SE5 8RS, UK; anne.greenough@ kcl.ac.uk

Received 8 January 2008 Accepted 2 January 2009 Published Online First

12 February 2009

\section{ABSTRACT}

Background: Hospitalisation due to respiratory syncytial virus (RSV) infection in the first 2 years after birth has been associated with increased healthcare utilisation and associated costs up to 5 years of age in children born prematurely at less than 32 weeks of gestation who developed bronchopulmonary dysplasia (BPD). A study was undertaken to determine whether hospitalisation due to RSV infection in the first 2 years was associated with increased morbidity and lung function abnormalities in such children at school age, and if any effects were influenced by age.

Methods: Healthcare utilisation and cost of care in years 5-7 were reviewed in 147 children and changes in healthcare utilisation between 0 and 8 years were assessed also using results from two previous studies. At age 8-10 years, 77 children had their lung function assessed and bronchial hyper-responsiveness determined. Results: Children hospitalised with RSV infection $(n=25)$ in the first 2 years had a greater cost of care related to outpatient attendance than those with a nonrespiratory or no admission ( $n=72$ ) when aged 5-7 years $(p=0.008)$. At $8-10$ years of age, children hospitalised with RSV infection $(n=14)$ had lower forced expiratory volume in $0.75 \mathrm{~s}\left(\mathrm{FEV}_{0.75}\right)(\mathrm{p}=0.015)$, $\mathrm{FEV}_{0.75} /$ forced vital capacity $(\mathrm{p}=0.027)$ and flows at $50 \%(p=0.034)$ and $75 \%(p=0.006)$ of vital capacity than children hospitalised for non-RSV causes $(n=63)$. Healthcare utilisation decreased with increasing age regardless of RSV hospitalisation status.

Conclusions: In prematurely born children who had BPD, hospitalisation due to RSV infection in the first 2 years is associated with reduced airway calibre at school age.

Respiratory syncytial virus (RSV) infection in previously healthy term-born infants is associated with increased respiratory problems at follow-up. ${ }^{1-3}$ Chronic respiratory morbidity also appears to be increased in prematurely born infants following symptomatic RSV infection. ${ }^{4-6}$ Prematurely born infants with or without bronchopulmonary dysplasia (BPD) who had an RSV lower respiratory tract infection had more days of cough and wheeze at follow-up at 1 year of corrected age. ${ }^{4}$ In addition, following hospitalisation for RSV infection in the first 2 years, healthcare utilisation was increased up to 2 years of age $e^{5}$ and in years $2-4$ inclusive $^{6}$ in prematurely born children with BPD. We have now re-examined our BPD cohort ${ }^{5}{ }^{6}$ with regard to their healthcare utilisation and associated cost of care between years 5 and 7 inclusive and assessed their lung function. Our aims were to determine whether, at school age, prematurely born children who had been hospitalised with an RSV infection in the first 2 years after birth still had an excess morbidity and whether this was associated with reduced lung function. In addition, by also examining the earlier results from the BPD cohort, ${ }^{56}$ we wished to determine if any effects on healthcare utilisation were influenced by age.

\section{METHODS}

The cohort consisted of children born at less than 32 weeks of gestation admitted during the first week after birth to one of four neonatal intensive care units who developed BPD. ${ }^{6}$ For this study, the parents were approached when their child was at least 8 years of age and, if they gave informed written consent, review was made of hospital admissions and community care when the children were aged 5-7 years inclusive and the associated cost of care calculated. Parents were asked to complete respiratory and health-related quality of life questionnaires regarding their child and to consent to their child undertaking lung function and skin prick testing.

\section{Measurements}

Healthcare utilisation and cost of care

Healthcare utilisation was assessed as previously described. ${ }^{56}$ The mean costs of each admission and outpatient attendance were calculated using data from the National Scheme of Reference Costs (2003) and medication costs from the British National Formulary prices. All primary care costs were those reported by Netten et al. ${ }^{7}$

\section{Respiratory questionnaire}

Questions were asked regarding known risk factors for respiratory morbidity. A family history of atopy was diagnosed if a parent or sibling had asthma, eczema and/or hay fever.

\section{Lung function testing}

This was undertaken in the four centres with standardisation between them. No child was tested within 2 weeks of an upper respiratory tract infection. Short-acting bronchodilators were withheld from midnight on the previous day if possible, but always at least $4 \mathrm{~h}$ before testing. At baseline, forced expiratory volume in $0.75 \mathrm{~s}\left(\mathrm{FEV}_{0.75}\right)$, forced vital capacity (FVC), forced expiratory flow (FEF) 
(measured from the top of the breath $\mathrm{FEF}_{75}$ is the flow at $75 \% ; \mathrm{FEF}_{50}$ is the flow at $50 \% ; \mathrm{FEF}_{25}$ at $25 \%$ of the vital capacity) and peak expiratory flow (PEF) were measured using a Lilley pneumotachograph (Vitalograph 2120, Vitalograph, Buckingham, UK). $\mathrm{FEV}_{0.75} / \mathrm{FVC}$ was calculated from the results. The lung function results were expressed as percentage predicted for height. ${ }^{89}$ Bronchial challenges were then performed. If the subject's $\mathrm{FEV}_{0.75}$ was $>80 \%$ of that predicted, a cold air challenge was performed, but if $\leqslant 80 \%$, a bronchodilator challenge was performed. For the cold air challenge, subfreezing $\left(-15^{\circ} \mathrm{C}\right)$ gas $(5 \%$ carbon dioxide, balance air) was inhaled for 4 min. ${ }^{10}$ Measurements of $\mathrm{FEV}_{0.75}$ were carried out every $2 \mathrm{~min}$ for a maximum of 12 min after the cold air challenge. A result was considered positive if, at any point, the maximum $\mathrm{FEV}_{0.75}$ fell by $12 \%$ from the maximum pre-challenge baseline. For the bronchodilator challenge, $100 \mu \mathrm{g}$ salbutamol (twice) was delivered. $\mathrm{FEV}_{0.75}$ was remeasured $20 \mathrm{~min}$ after the bronchodilator and a result was considered positive in there was an increase from baseline of at least $15 \%$.

\section{Skin prick testing}

Sensitisation to six common allergens (dog hair, cat hair, house dust mite, six grass mix, tree mix and mould) was assessed. Children were defined as atopic if they had a positive reaction to at least one allergen.

\section{Health-related quality of life}

Parents were sent the Health Utilities Index (HUI 2 and 3) and asked to complete the 15 questions to reflect their child's health over the previous 4 weeks. ${ }^{6}$

\section{Analysis of data}

Only results from children who had taken part in our two previous studies ${ }^{56}$ and this follow-up at school age were included. The children were divided into three groups according to admission diagnosis in the first 2 years: (1) RSV; (2) other respiratory; and (3) non-respiratory (non-respiratory/no admission). The RSV group had at least one hospital admission with a proven RSV infection (RSV antigen identified on a nasopharyngeal aspirate (NPA)). Children in the other respiratory group

Table 1 Neonatal demographic characteristics by hospital admission status in the first 2 years

\begin{tabular}{lccc}
\hline & $\begin{array}{l}\text { RSV } \\
(\mathbf{n}=\mathbf{2 5})\end{array}$ & $\begin{array}{l}\text { Other respiratory } \\
(\mathbf{n}=\mathbf{5 0})\end{array}$ & $\begin{array}{l}\text { Non-respiratory } \\
(\mathbf{n}=\mathbf{7 2})\end{array}$ \\
\hline Gestational age (weeks) & $26(24-31)$ & $27(23-31)$ & $27(25-31)$ \\
Birth weight (g) & $820(640-1960)$ & $1013(630-1696)$ & $937(510-1566)$ \\
Maternal steroids (\%) & 77 & 87 & 84 \\
Surfactant (\%) & 88 & 86 & 79 \\
IPPV (\%) & 96 & 98 & 94 \\
CPAP (\%) & 67 & 47 & 66 \\
HFOV (\%) & 4 & 7 & 0 \\
Nitric oxide (\%) & 4 & 8 & 1 \\
PDA (\%) & 24 & 38 & 32 \\
Air leak (\%) & 8 & 22 & 9 \\
Postnatal dexamethasone (\%) & 38 & 44 & 33 \\
Duration of neonatal & $85(16-360)$ & $78(10-464)$ & $64(2-827)$ \\
admission (days) & & & \\
Home oxygen (\%) & 40 & 50 & 32 \\
\hline
\end{tabular}

Data are presented as median (range) or percentage.

CPAP, continuous positive airway pressure; HFOV, high frequency oscillation ventilation; IPPV, intermittent positive pressure ventilation; PDA, patent ductus arteriosus; RSV, respiratory syncytial virus. had an admission with probable bronchiolitis (clinical diagnosis but the NPA was negative or no result available) or another respiratory problem (chest infection, croup, apnoea, asthma, wheeze, pneumonia, upper respiratory tract infection, dyspnoea and/or overnight oxygen saturation monitoring). Missing data were not imputed. Comparisons were also made between children with proven RSV infection and the others as indicated. To determine if there were statistically significant differences between groups for categorical data, differences were assessed using the Fisher exact test or $\chi^{2}$ test as appropriate and a hierarchical analysis was performed on continuous data. The groups were compared using the Kruskal-Wallis test. Only if there was evidence of variation $(p<0.10)$ was the RSV group compared with each of the other two groups using the two degrees of freedom to perform the two pairwise comparisons. Within each group, the variation with age was analysed using the two-way analysis of variance on ranks with main effects, patients and age. Where a significant difference was found, it was investigated within the ANOVA using a Bonferroni correction. The group by age interaction was examined to determine whether the change over time differed between groups.

\section{RESULTS}

The original study included 235 infants. ${ }^{5}$ Written informed consent for their child to participate in this study was obtained from 160 parents. Thirteen children who took part in this school age follow-up had not participated in the second study, ${ }^{6}$ hence their results were not included (see online appendix, fig 1). None had received RSV immunoprophylaxis.

A total of 147 children took part in the previous studies ${ }^{5}$ and in this school age study (ie, had complete follow-up data). The demographics of the children who had complete follow-up data differed from those who did not only in that fewer had received surfactant $(p=0.012)$ (see online appendix 1). The 77 children who underwent lung function testing differed significantly in their demographics from the other 70 children who had complete follow-up data only in that more had received continuous positive airway pressure $(p=0.003$, see online appendix 2).

There were no significant differences in the demographics according to hospitalisation status in the first 2 years between the groups (table 1). In years 5-7 neither the hospital admission rate nor the number of GP visits differed significantly between the RSV group and the other two groups, but the RSV group had more outpatient visits than the non-respiratory group $(p=0.007$, table 2$)$. Overall, there were no significant differences in the cost of care for hospital stay, GP visits or prescriptions between the RSV group and the other two groups. The cost of outpatient attendances $(p=0.008)$ was significantly higher and the total cost of care tended to be higher $(p=0.05)$ in the RSV group than in the non-respiratory group (table 3 ). The total cost of care $(p=0.04)$ and the costs for prescriptions $(p=0.05)$ and hospital admissions $(p=0.02)$ were higher in the other respiratory groups than in the non-respiratory group (table 3 ). The total respiratory cost of care differed significantly between the other respiratory and non-respiratory groups $(p=0.004$, see online appendix 3$)$.

Data from the respiratory questionnaire demonstrated a trend for more of the RSV group than the rest of the cohort who completed the questionnaire to have a family history of eczema $(p=0.051)$ and fewer to have wheeze ever $(p=0.043)$; otherwise, there were no significant differences between the 
Table 2 Healthcare utilisation at age 5-7 years inclusive by hospital admission status in the first 2 years

\begin{tabular}{lllll}
\hline & $\begin{array}{l}\text { RSV } \\
(\mathbf{n}=\mathbf{2 5})\end{array}$ & $\begin{array}{l}\text { Other respiratory } \\
(\mathbf{n}=\mathbf{5 0})\end{array}$ & $\begin{array}{l}\text { Non-respiratory } \\
(\mathbf{n}=\mathbf{7 2})\end{array}$ & $\begin{array}{l}\text { p Value between the } \\
\text { three groups }\end{array}$ \\
\hline Hospital admission & $0.76,(0),(0-10)$ & $0.88,(0),(0-6)$ & $0.36,(0),(0-10)$ & 0.046 \\
Outpatient attendances & $8.84,(4),(0-32)$ & $5.24,(4),(0-24)$ & $4.35,(2),(0-27)$ & 0.023 \\
GP visits & $9.00,(6),(0-30)$ & $6.94,(6),(1-21)$ & $7.42,(5),(0-52)$ & 0.757 \\
\hline
\end{tabular}

Data are presented as mean, (median), (range) per child over the 3-year period.

RSV, respiratory syncytial virus.

groups (table 4). Similar results (data not shown) were found for the children who underwent lung function testing.

The median HUI 2 and HUI 3 scores of the RSV group did not differ significantly from those of the other respiratory or nonrespiratory groups (data not shown).

Lung function measurements were undertaken in 77 children. The 14 children in the RSV group had similar antenatal/ neonatal demographic characteristics to the rest of the cohort who had lung function testing (non-RSV, table 5) and to the other respiratory and non-respiratory groups (table 6). The RSV group had significantly lower baseline mean $\mathrm{FEV}_{0.75}, \mathrm{FEV}_{0.75} / \mathrm{FVC}$, mid forced expiratory flow $\left(\mathrm{FEF}_{50}\right)$ and end forced expiratory flow $\left(\mathrm{FEF}_{75}\right)$ to the non-RSV group (table 5). Comparison of the three groups showed that the baseline $\mathrm{FEV}_{0.75}(\mathrm{p}=0.018), \mathrm{FEV}_{0.75} / \mathrm{FVC}(\mathrm{p}=0.021)$ and $\mathrm{FEF}_{50}$ $(p=0.036)$ of the RSV group were significantly lower than the non-respiratory group; the $\mathrm{FEV}_{0.75}$ of the RSV group was lower than both the other respiratory $(p=0.042)$ and the nonrespiratory $(p=0.018)$ groups and the $\mathrm{FEF}_{75}$ of the RSV group was also lower than both the other respiratory $(p=0.030)$ and the non-respiratory $(p=0.005)$ groups (table 6$)$. There were no significant differences between the three groups with regard to their median peak expiratory flow (PEF), FVC and $\mathrm{FEF}_{25}$ (table 6).

Twenty-nine children underwent a cold air challenge and 65 undertook a bronchodilator challenge (28 after a cold air challenge). None of the four in the RSV group and seven of the 25 in the non-RSV group had a positive response to cold air challenge $(p=0.552)$. Following the cold air challenge, the median change in $\mathrm{FEV}_{0.75}$ in the RSV group was $1.62 \%$ (range $-3.9 \%$ to $6.3 \%$ ), which did not differ significantly from the change in the rest of the cohort who had lung function testing (mean $0.23 \%$, range $-9.43 \%$ to $6.71 \% ; p=0.48$ ) or the other respiratory group (mean $2.01 \%$, range $-5.95 \%$ to $5.56 \%$ ) or the non-respiratory group (median $0 \%,-9.43 \%$ to $6.71 \%$ ). Three of $12(25 \%)$ in the RSV group and 16 of $53(30 \%)$ had a positive response to the bronchodilator challenge $(p=1.00)$; this included 8 of $23(35 \%)$ in the other respiratory group and 8 of $30(27 \%)$ in the non-RSV group. The median change in $\mathrm{FEV}_{0.75}$ in the RSV group (10.8\%, range $-0.95 \%$ to $27.2 \%$ ) was similar to that in the non-RSV group $(10.0 \%$, range $-7.9 \%$ to $31.4 \%$, $p=0.565)$ and the other respiratory (8.7\%, range $-7.9 \%$ to 23.6$)$ and non-respiratory $(10.4 \%$, range $-6.5 \%$ to $31.4 \%$ ) groups. Children who had a history of cough tended to have a lower mean $\mathrm{FEV}_{0.75}(\mathrm{p}=0.069)$ but not $\mathrm{FEF}_{75}$ than those without a cough history; there were no significant differences in $\mathrm{FEV}_{0.75}$ and $\mathrm{FEF}_{75}$ between those with and without wheeze. There were no significant correlations between cough and wheeze severity and $\mathrm{FEF}_{0.75}$ and $\mathrm{FEF}_{75}$, but the children who had cough were more likely to wheeze $(p<0.001)$. Sixty-two children underwent skin prick testing; $2 / 12$ in the RSV group had a positive test compared with 10/50 in the non-RSV group ( $p=1.00), 3 / 18$ in the other respiratory group and $7 / 32$ in the non-respiratory group.

In all three groups, healthcare utilisation and the related cost of care decreased with increasing postnatal age (figs 1, 2 and 3). There were significant differences between the RSV group and the rest of the cohort regarding hospital admissions $(p<0.001)$.

\section{DISCUSSION}

We report the first long-term follow-up of prematurely born children who had had BPD and subsequent early hospitalisation due to RSV. Those who had been hospitalised with RSV required significantly more outpatient attendances and related cost of care in years 5-7 than those who had a non-respiratory or no admission in the first 2 years. In addition, the RSV group had significantly worse lung function at 8-10 years of age. Children were only included in the RSV group if they had an NPA positive for RSV. We cannot exclude the possibility that children in the other two groups may have had a hospitalisation due to RSV infection, but their NPA was negative or not reported; nevertheless, we report significant differences between the groups.

We were unable to follow all of the original cohort ${ }^{5}$ and it is possible that data from the "missing" children might have altered our results. However, comparison of their antenatal and neonatal demographic characteristics showed that the only significant difference between those followed and not followed

Table 3 Cost of care (UKf) at age 5-7 years inclusive by hospital admission status in the first 2 years

\begin{tabular}{|c|c|c|c|c|}
\hline & RSV & Other respiratory & Non-respiratory & $\begin{array}{l}\text { p Value between } \\
\text { the three groups }\end{array}$ \\
\hline Hospital admission & $649,(0),(0-8286)$ & $925,(0),(0-8507)$ & $602,(0),(0-23800)$ & 0.055 \\
\hline Outpatient attendances & $815,(288),(0-3646)$ & $450,(289),(0-2134)$ & $376,(156),(0-2406)$ & 0.026 \\
\hline GP visits & 199, (126), (0-720) & $150,(128),(0-438)$ & 168, (107), (0-1508) & 0.721 \\
\hline \multicolumn{5}{|l|}{ Prescriptions* } \\
\hline All & 204, (28), (0-3935) & $545,(30),(0-14129)$ & $111,(13),(0-3333)$ & 0.094 \\
\hline Respiratory & 18.8, (10.6), (0-119) & $56.8,(9.6),(0-556)$ & $11.5,(1.2),(0-270)$ & 0.003 \\
\hline Total & 2120, (962), (86-17379) & $2287,(852),(0-15041)$ & $1481,(340),(0-28455)$ & 0.049 \\
\hline
\end{tabular}

Data are presented as mean, (median), (range) per child over the 3 -year period.

*Expressed as the number of respiratory prescriptions per child over the 3-year period. Respiratory prescriptions included antiasthma medication and antibiotics for lower respiratory tract infections.

RSV, respiratory syncytial virus. 
Table 4 Results of the respiratory questionnaire by hospital admission status in the first 2 years

\begin{tabular}{|c|c|c|c|c|}
\hline & $\begin{array}{l}\text { RSV } \\
(n=17)\end{array}$ & $\begin{array}{l}\text { Other respiratory } \\
(n=40)\end{array}$ & $\begin{array}{l}\text { Non-respiratory } \\
(n=52)\end{array}$ & $\begin{array}{l}\text { p Value between the } \\
\text { three groups }\end{array}$ \\
\hline \multicolumn{5}{|l|}{ Maternal smoking } \\
\hline In pregnancy & $18 \%$ & $23 \%$ & $24 \%$ & 0.879 \\
\hline Currently & $18 \%$ & $25 \%$ & $16 \%$ & 0.527 \\
\hline Breast fed & $71 \%$ & $51 \%$ & $49 \%$ & 0.289 \\
\hline \multicolumn{5}{|l|}{ Family history } \\
\hline Asthma & $38 \%$ & $33 \%$ & $33 \%$ & 0.936 \\
\hline Eczema* & $50 \%^{*}$ & $28 \%$ & $25 \%$ & 0.142 \\
\hline Hay fever & $53 \%$ & $36 \%$ & $47 \%$ & 0.414 \\
\hline Long haired pets & $35 \%$ & $29 \%$ & $33 \%$ & 0.867 \\
\hline Parents homeowners & $88 \%$ & $79 \%$ & $81 \%$ & 0.512 \\
\hline Home oxygen $>2$ years & $6 \%$ & $8 \%$ & $0 \%$ & 0.077 \\
\hline \multicolumn{5}{|l|}{ Cough } \\
\hline Ever & $47 \%$ & $50 \%$ & $58 \%$ & 0.656 \\
\hline More than once a week & $12 \%$ & $23 \%$ & $12 \%$ & 0.319 \\
\hline \multicolumn{5}{|l|}{ Wheeze } \\
\hline Ever & $12 \%$ & $48 \%$ & $29 \%$ & 0.022 \\
\hline More than once a week & $0 \%$ & $8 \%$ & $0 \%$ & 0.319 \\
\hline Use of medication & $12 \%$ & $33 \%$ & $15 \%$ & 0.081 \\
\hline
\end{tabular}

*Only 16 in the RSV group answere
RSV, respiratory syncytial virus.

was the proportion receiving surfactant. In addition, the only significant difference in the demographics of children who did and did not take part in the lung function testing was the proportion who received CPAP. We therefore feel our results are generalisable to prematurely born children with BPD.

The present healthcare utilisation results are consistent with our previous findings ${ }^{6}$ in that the children with early hospitalisation due to RSV had more outpatient attendances

Table 5 Baseline lung function results by RSV hospital admission status in the first 2 years

\begin{tabular}{|c|c|c|c|}
\hline & $\begin{array}{l}\text { RSV group } \\
(\mathrm{n}=14)\end{array}$ & $\begin{array}{l}\text { Non-RSV group } \\
(\mathrm{n}=63)\end{array}$ & p Value \\
\hline Gestational age (weeks) & $26(24-31)$ & $28(24-31)$ & 0.335 \\
\hline Birth weight (g) & $820(650-1826)$ & $964(515-1520)$ & 0.353 \\
\hline Maternal steroids (\%) & 85 & 82 & 1.000 \\
\hline Surfactant (\%) & 86 & 81 & 1.000 \\
\hline IPPV (\%) & 100 & 97 & 1.000 \\
\hline CPAP (\%) & 86 & 68 & 0.324 \\
\hline HFOV (\%) & 8 & 5 & 0.563 \\
\hline Nitric oxide (\%) & 7 & 7 & 1.000 \\
\hline PDA (\%) & 29 & 37 & 0.759 \\
\hline Air leak (\%) & 14 & 14 & 1.000 \\
\hline Postnatal dexamethasone (\%) & 36 & 38 & 0.890 \\
\hline \multicolumn{4}{|l|}{ At lung function } \\
\hline Age (years) & $10.5(8.9-12.1)$ & $10.3(8.5-11.9)$ & 0.460 \\
\hline Height $(\mathrm{cm})$ & 135 (119-151) & $139(122-160)$ & 0.488 \\
\hline Weight $(\mathrm{kg})$ & $29.7(18.6-39.4)$ & $32.5(20.4-65.0)$ & 0.074 \\
\hline PEF* & $67.8(27.1-99.3)$ & $76(27-140)$ & 0.102 \\
\hline $\mathrm{FVC}^{*}$ & $89.6(75-125)$ & $94.2(68.7-125)$ & 0.240 \\
\hline $\mathrm{FEV}_{0.75}{ }^{*}$ & $68.2(48-99)$ & $81.9(47-133)$ & 0.015 \\
\hline $\mathrm{FEV}_{0.75} / \mathrm{FVC}$ & $78.9(52.9-97.1)$ & $86.4(58-116.2)$ & 0.027 \\
\hline $\mathrm{FEF}_{25}{ }^{*}$ & $67.0(32-94)$ & $75.4(27.7-131)$ & 0.362 \\
\hline $\mathrm{FEF}_{50}{ }^{*}$ & $50.7(22.5-93)$ & $70.1(22-165)$ & 0.034 \\
\hline $\mathrm{FEF}_{75}{ }^{*}$ & $40.7(24-60)$ & $57.2(11-221)$ & 0.006 \\
\hline
\end{tabular}

*Results are expressed as percentage predicted for height.

CPAP, continuous positive airway pressure; $F E F$, forced expiratory flow; $\mathrm{FEF}_{25}$, flow at $25 \%$ of vital capacity; $\mathrm{FEF}_{50}$, flow at $50 \%$ of vital capacity; $\mathrm{FEF}_{75}$, flow at $75 \%$ of vital capacity; FEV, forced expiratory volume; FVC, forced vital capacity; HFOV, high frequency oscillatory ventilation; IPPV, intermittent positive pressure ventilation; PDA, patent ductus arteriosus; PEF, peak expiratory flow; RSV, respiratory syncytial virus. and a greater associated cost of care. In years $2-4$, however, the RSV group also had significantly greater overall cost of care and worse health-related quality of life, suggesting they had suffered greater morbidity at the younger age. ${ }^{6}$ It is possible that those we could not follow had been more severely affected, but they had similar antenatal/neonatal demographics to those who were followed. An alternative explanation is that any effect of RSV infection on chronic morbidity in prematurely born children diminishes with increasing age, which is consistent with the results of some studies of children born at term. ${ }^{11}$ In one cohort ${ }^{1}$ the prevalence of respiratory symptoms, although remaining significantly higher in the RSV group, was lower when the children were 9-10 years of age than when previously reviewed ${ }^{2}$ and, in another, although RSV lower respiratory tract infections were associated with an increased risk of infrequent and frequent wheeze at 6 years of age, the risk markedly decreased with increasing age and was not significant at age $13 .{ }^{11}$ In another study, ${ }^{12}$ however, even at 13 years of age asthma/recurrent wheezing was still markedly higher in the RSV group (43\% vs 8\%). In addition, in the RSV group, sensitisation to common inhaled allergens was more common. In contrast, other studies have reported no excess of wheezing at 10 years of age ${ }^{2}$ and no significant differences in the rates of asthma or allergic sensitisation after $18-20$ years. ${ }^{13}$ It is possible that these differences may relate to whether hospitalisation was required for the RSV lower respiratory tract infection, ${ }^{41}$ age at admission $^{13}$ and/or the allergen load.

Healthcare utilisation decreased significantly with increasing postnatal age in all three groups in this study, yet there were significant differences between the RSV group and the nonrespiratory group at the age of 5-7 years. Whether early RSV infection impacts adversely on prematurely born children when they are adolescents requires investigation.

Both the RSV and non-RSV group had lung function results on average below that predicted for their height, consistent with our study population being born very prematurely and having had BPD. ${ }^{14}{ }^{15}$ Nevertheless, the RSV group had significantly worse lung function than those without previous hospitalisation for RSV infection. The RSV group had significantly lower $\mathrm{PEF}, \mathrm{FEV}_{0.75}, \mathrm{FEF}_{50}$ and $\mathrm{FEF}_{75}$, indicating 
Table 6 Baseline lung function results by hospital admission status in the first 2 years

\begin{tabular}{|c|c|c|c|c|}
\hline & $\begin{array}{l}\text { RSV } \\
(n=14)\end{array}$ & $\begin{array}{l}\text { Other respiratory } \\
(\mathrm{n}=27)\end{array}$ & $\begin{array}{l}\text { Non-respiratory } \\
(\mathrm{n}=36)\end{array}$ & $\begin{array}{l}\text { p Value between } \\
\text { the three groups }\end{array}$ \\
\hline Gestational age weeks) & $26(24-31)$ & $27(24-31)$ & $28(25-31)$ & 0.449 \\
\hline Birth weight (g) & $820(650-1826)$ & 1012 (680-1434) & 927 (515-1520) & 0.552 \\
\hline Maternal steroids (\%) & 85 & 89 & 78 & 0.743 \\
\hline Surfactant (\%) & 86 & 85 & 78 & 0.733 \\
\hline IPPV (\%) & 100 & 96 & 97 & 1.000 \\
\hline CPAP (\%) & 86 & 48 & 83 & 0.006 \\
\hline HFOV & 8 & 12 & 0 & 0.086 \\
\hline Nitric oxide & 7 & 11 & 3 & 0.410 \\
\hline PDA & 29 & 37 & 33 & 0.709 \\
\hline Air leak & 14 & 22 & 8 & 0.320 \\
\hline Postnatal & 36 & 48 & 29 & 0.320 \\
\hline \multicolumn{5}{|l|}{ Dexamethasone } \\
\hline \multicolumn{5}{|l|}{ At lung function } \\
\hline Age (years) & $10.5(8.9-12.1)$ & $10.2(8.5-11.8)$ & 10.4 8.9-11.9) & 0.569 \\
\hline Height $(\mathrm{cm})$ & 135 (119-151) & 137 (122-159) & $141(123-160)$ & 0.204 \\
\hline Weight (kg) & $29.7(18.6-39.4)$ & $30.0(21.6-46.9)$ & $34.4(20.4-65.0)$ & 0.038 \\
\hline PEF* & $67.8(27.1-99.3)$ & 75.7 (59.1-121.0) & $77.4(27.4-140)$ & 0.261 \\
\hline $\mathrm{FVC}^{*}$ & $89.6(75.1-124.5)$ & $94.7(72.3-125.1)$ & $93.1(68.7-118.3)$ & 0.496 \\
\hline $\mathrm{FEV}_{0.75^{*}}$ & $68.2(48-99)$ & $82.3(53.7-105.3)$ & $81.5(47.2-132.9)$ & 0.051 \\
\hline $\mathrm{FEV}_{0.75} / \mathrm{FVC}$ & $78.9(52.9-97.1)$ & $87.2(60-96.7)$ & $86(63-116.2)$ & 0.070 \\
\hline $\mathrm{FEF}_{25}{ }^{*}$ & $67.0(32-94)$ & 79.9 (35.8-107.4) & $74.9(27.7-131.2)$ & 0.651 \\
\hline $\mathrm{FEF}_{50}{ }^{*}$ & $50.7(22.5-92.9)$ & $68.5(23.2-109.8)$ & $71.7(21.8-165.4)$ & 0.077 \\
\hline $\mathrm{FEF}_{75}{ }^{*}$ & $40.7(24-60)$ & $52.7(11.5-101.6)$ & $60.7(14.5-220.6)$ & 0.012 \\
\hline
\end{tabular}

${ }^{*}$ Results are expressed as percentage predicted for height.

CPAP, continuous positive airway pressure; $\mathrm{FEF}$, forced expiratory flow; $\mathrm{FEF}_{25}$, flow at $25 \%$ of vital capacity; $\mathrm{FEF}_{50}$, flow at $50 \%$ of vital capacity; $\mathrm{FEF}_{75}$, flow at $75 \%$ of vital capacity; FEV, forced expiratory volume; $\mathrm{FVC}$, forced vital capacity; HFOV, high frequency oscillatory ventilation; IPPV, intermittent positive pressure ventilation; PDA, patent ductus arteriosus; PEF, peak expiratory flow; RSV, respiratory syncytial virus.

narrower airway calibre. The abnormalities were particularly pronounced in the small airways, as evidenced by the greater differences between the groups in $\mathrm{FEF}_{75}$ compared with $\mathrm{FEF}_{50}$ and $\mathrm{FEF}_{25}$. Comparison of the lung function results of the three groups showed that differences in lung function were most marked between the RSV group and the non-respiratory group, with significant differences in the $\mathrm{FEV}_{0.75}, \mathrm{FEV}_{0.75} / \mathrm{FVC}, \mathrm{FEF}_{50}$ and $\mathrm{FEF}_{75}$. Except for the $\mathrm{FEF}_{75}$ results, there were no significant differences in the lung function results of the RSV group and the other respiratory group. Greater proportions of the other respiratory group had "wheeze ever" and required medications than the RSV group; it is thus tempting to speculate that at least some of the other respiratory group had asthma. Our results demonstrating narrower airway calibre in prematurely born children who had had an RSV infection are consistent with the majority of studies of previously healthy infants who have

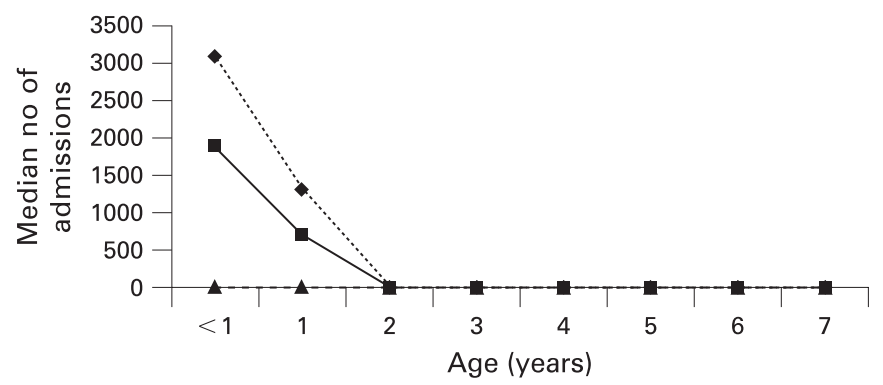

Figure 1 Hospital admissions related to age. Data are plotted as the median number of hospital admissions per child per year in each group; diamonds; RSV-proven; squares, other respiratory; triangles, nonrespiratory. suffered an RSV lower respiratory tract infection in the first years after birth. ${ }^{12}{ }^{116-24}$ It has, however, been shown that diminished lung function-particularly abnormalities of small airway function - may predispose to symptomatic RSV lower respiratory tract infections in infants born at term. ${ }^{25-27}$ Our preliminary results also suggest that prematurely born infants who develop a symptomatic RSV lower respiratory tract infection have worse premorbid lung function. ${ }^{28}$ It is therefore not certain whether the abnormalities in lung function seen at follow-up are the results of the RSV infection or reflect premorbid abnormal lung function. This requires assessing in a prospective study including serial lung function measurements before and after RSV infection.

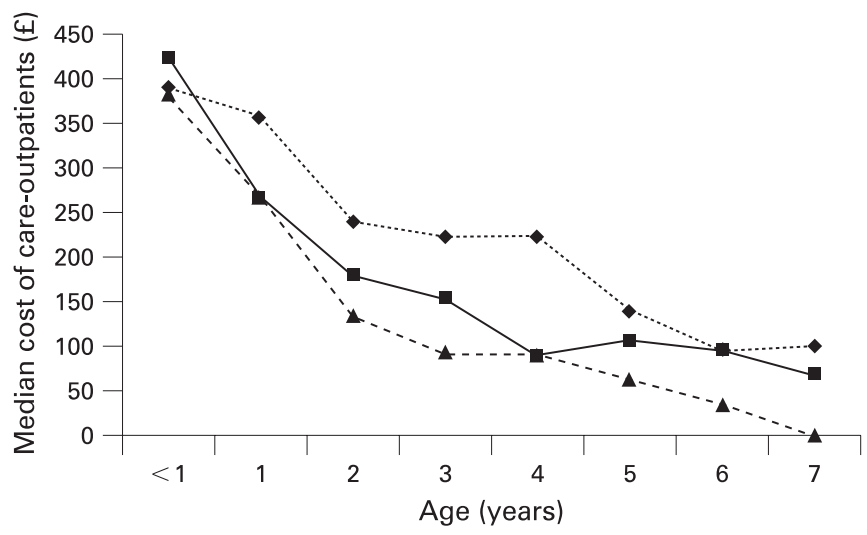

Figure 2 Cost of care of outpatient attendance related to age. Data are presented as median costs per child per year per group; diamonds, RSVproven; squares, other respiratory; triangles, non-respiratory. 


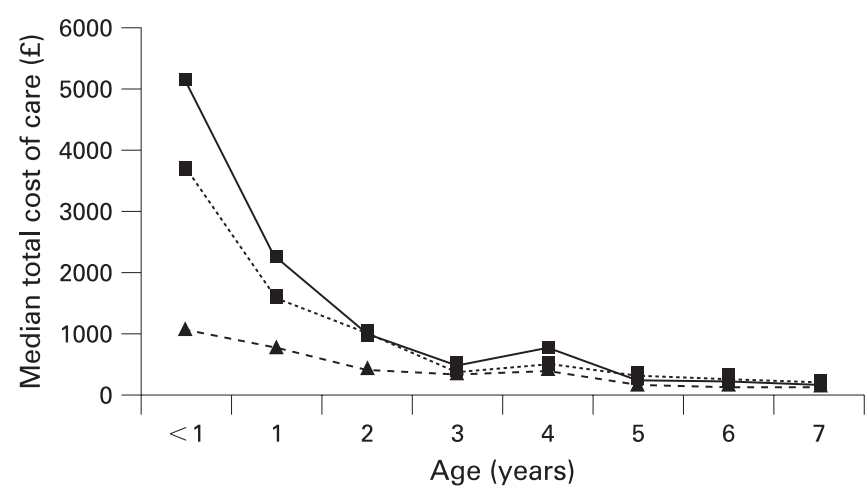

Figure 3 Total cost of care related to age. Data are presented as median costs per child per year per group; diamonds, RSV-proven; squares, other respiratory; triangles, non-respiratory.

We did not find significant differences in the proportion of children with bronchial hyperreactivity between the groups. We used a relatively conservative baseline $\mathrm{FEV}_{0.75}$ to determine whether the children should be subjected to a cold air challenge and this may have biased our results. The bronchial hyperreactivity findings in children born at term following RSV infection are conflicting. ${ }^{1} 211^{20}{ }^{23}$ It has been suggested that any association between RSV lower respiratory tract infection and bronchial hyperreactivity may be explained by atopy, as children admitted to hospital with an RSV infection were more likely to be atopic. ${ }^{29}$ In three studies, ${ }^{12}{ }^{23}$ however, atopy was not more common in the RSV group. In this study we found no significant difference between the RSV and non-RSV groups in the proportions of children with a family history of atopy, but eczema tended to be more common in the RSV group. The relevance of the latter finding is unclear. Studies assessing allergic sensitisation following RSV infection have yielded conflicting results. ${ }^{1-3}$ 30-32 Unfortunately, few agreed to skin prick testing in this study, so we are unable to determine whether RSV infection is associated with increased allergic sensitisation in prematurely born children.

In conclusion, in all three groups, healthcare utilisation and related cost of care decreased with increasing age. Those who were hospitalised with RSV in the first 2 years after birth, however, had more outpatient attendances and a greater related cost of care between the ages of 5-7 inclusive and worse lung function than children not admitted in the first 2 years for a respiratory cause. Whether these results reflect worse premorbid lung function in prematurely born children admitted to hospital with an RSV infection merits testing. It would also be important to assess in a randomised trial whether RSV preventive therapy reduced healthcare utilisation at follow-up.

Funding: The research nurses were funded by Abbott Laboratories Ltd and Medlmmune.

Competing interests: Abbott Laboratories market palivizumab, a monoclonal antibody for prophylaxis against RSV. AG, WL and PC have received honoraria for speaking at Abbott sponsored conferences. TL and JB are employees of Abbott Laboratories. TL was the clinical monitor and JB was the clinical project manager for this study.

Ethics approval: The study was approved by the local research ethics committees of the four hospitals.

\section{REFERENCES}

1. Noble V, Murray M, Webb MSC, et al. Respiratory status and allergy nine to ten years after acute bronchiolitis. Arch Dis Child 1997;76:315-9.

2. Pullen CR, Hey EN. Wheezing, asthma and pulmonary dysfunction 10 years after infection with respiratory syncytial virus in infancy. BMJ 1982;284:1665-9.

3. Sigurs N, Bjarnson R, Sigurbergsson F, et al. Respiratory syncytial virus bronchiolitis in infancy is an important risk factor for asthma and allergy at age seven. Am J Respir Crit Care Med 2000;161:1501-7.

4. Broughton S, Roberts A, Fox G, et al. Prospective study of healthcare utilisation and respiratory morbidity due to RSV infection in prematurely born infants. Thorax 2005;60:1039-44.

5. Greenough A, Alexander J, Burgess $S$, et al. Health care utilisation of infants with chronic lung disease, related to hospitalisation for RSV infection. Arch Dis Child 2001;85:463-8.

6. Greenough A, Alexander J, Burgess $\mathrm{S}$, et al. Health care utilisation of prematurely born, preschool children related to hospitalisation for RSV infection. Arch Dis Child 2004;89:673-8.

7. Netten A, Dennett J, Knight J. Unit costs of health and social care. University of Kent: Personal Social Services Research Unit, 2004.

8. Rosenthal M, Bain SH, Cramer D, et al. Lung function in white children aged 4 to 19 years: 1- Spirometry. Thorax 1993;48:794-802.

9. Rosenthal M, Cramer D, Bain SH, et al. Lung function in white children aged 4 to 19 years: 11 - Single breath analysis and plethysmography. Thorax 1993;48:803-8.

10. Sylvester KP, O'Connor B, Farebrother HM, et al. Cold air and exercise challenge influence of minute ventilation. J Asthma 2007;44:143-7.

11. Stein RT, Sherrill D, Morgan WJ, et al. Respiratory syncytial virus in early life and risk of wheeze and allergy by age 13 years. Lancet 1999;354:541-5.

12. Sigurs N, Gustafsson PM, Bjarnason R, et al. Severe respiratory syncytial virus bronchiolitis in infancy and asthma and allergy at age 13. Am J Respir Crit Care Med 2005; 171:137-41.

13. Korppi M, Piippo-Savolainen E, Korhonen K, et al. Respiratory morbidity 20 years after RSV infection in infancy. Pediatr Pulmonol 2004;38:155-60.

14. Koumbourlis AC, Motoyama EK, Mutich RL, et al. Longitudinal follow up of lung function from childhood to adolescence in prematurely born patients with neonatal chronic lung disease. Pediatr Pulmonol 1996;21:28-34.

15. Northway WH Jr, Rosan RC, Porter DY. Pulmonary disease following respiratory therapy of hyaline membrane disease. N Engl J Med 1967;276:357-68.

16. Stokes GM, Milner AD, Hodges IG, et al. Lung function abnormalities after acute bronchiolitis. J Pediatr 1981;98:871-4.

17. Seidenberg J, Masters IB, Hudson I, et al. Disturbance in respiratory mechanics in infants with bronchiolitis. Thorax 1989;44:660-7.

18. Dezateux C, Fletcher ME, Dundas I, et al. Infant respiratory function after RSVproven bronchiolitis. Am J Respir Crit Care Med 1997;155:1349-55.

19. Hall CB, Hall WJ, Gala CL, et al. Long-term prospective study in children after respiratory syncytial virus infection. J Pediatr 1984;105:358-64.

20. Turner SW, Young S, Landau LI, et al. Reduced lung function both before bronchiolitis and at 11 years. Arch Dis Child 2002;87:417-20.

21. McConnochie KM, Mark JD, McBride JT, et al. Normal pulmonary function measurements and airway reactivity in childhood after mild bronchiolitis. J Pediatr 1985; 107:54-8.

22. Mok JY, Simpson H. Outcome of acute lower respiratory tract infection in infants: preliminary report of seven-year follow-up study. BMJ 1982;285:333-7.

23. Sims DG, Downham MA, Gardner PS, et al. Study of 8-year-old children with a history of respiratory syncytial virus bronchiolitis in infancy. BMJ 1978;1:11-4

24. Kattan M, Keens TG, Lapierre JG, et al. Pulmonary function abnormalities in symptom-free children after bronchiolitis. Pediatrics 1977;59:683-8.

25. Young S, O'Keefe PT, Arnott J, et al. Lung function, airway responsiveness and respiratory symptoms before and after bronchiolitis. Arch Dis Child 1995;72:16-24.

26. Martinez FD, Morgan WJ, Wright AL, et al. Initial airway function is a risk factor for recurrent wheezing respiratory illnesses during the first three year of life. Group Health Medical Associates. Am Rev Respir Dis 1991;143:312-6.

27. Martinez FD, Morgan WJ, Wright AL, et al. Diminished lung function as a predisposing factor for wheezing respiratory illness in infants. N Engl J Med 1988:319:1112-7.

28. Broughton S, Bhat R, Roberts A, et al. Diminished lung function, RSV infection and respiratory morbidity in prematurely born infants. Arch Dis Child 2006;91:26-30.

29. Henderson FW, Stewart PW, Burchinal MR, et al. Respiratory allergy and the relationship between early childhood lower respiratory illness and subsequent lung function. Am Rev Respir Dis 1992;145:283-90.

30. Carlsen $\mathbf{K H}$, Larsen S, Bjerve 0 , et al. Acute bronchiolitis: predisposing factors and characterization of infants at risk. Pediatr Pulmonol 1987;3:153-60.

31. Sims DG, Gardener PS, Weightman D, et al. Atopy does not predispose to RSV bronchiolitis or postbronchiolitic wheezing. BMJ 1981;282:2086-8.

32. Murray M, Webb C, O'Callaghan A, et al. Respiratory status and allergy after bronchiolitis. Arch Dis Child 1992:67:482-7. 